\title{
Make Fitness Fun: Could Novelty Be the Key Determinant for Physical Activity Adherence?
}

\author{
Nemanja Lakicevic ${ }^{1,2}$, Ambra Gentile $^{1,2 *}$, Samira Mehrabi ${ }^{3}$, Samuel Cassar ${ }^{4}$, Kate Parker ${ }^{4}$, \\ Roberto Roklicer ${ }^{5}$, Antonino Bianco ${ }^{2}$ and Patrik Drid ${ }^{5}$ \\ ${ }^{1}$ Program in Health Promotion and Cognitive Sciences, University of Palermo, Palermo, Italy, ${ }^{2}$ Department of Psychology, \\ Educational Science and Human Movement, University of Palermo, Palermo, Italy, ${ }^{3}$ Department of Kinesiology, Faculty of \\ Applied Health Science, University of Waterloo, Waterloo, ON, Canada, ${ }^{4}$ School of Exercise and Nutrition Sciences, Institute \\ for Physical Activity and Nutrition, Deakin University, Geelong, VIC, Australia, ${ }^{5}$ Faculty of Sport and Physical Education, \\ University of Novi Sad, Novi Sad, Serbia
}

Keywords: exercise novelty, flow state, motivation, sport participation, exercise prescription, health benefits

\section{INTRODUCTION}

\section{The Determinants of Individuals' Physical Activity Engagement Over Time}

The benefits of physical activity (PA) are well known and are extensively delineated in the scientific literature. Regular participation in PA, or exercise as its subset (structured, preplanned form of

\section{OPEN ACCESS}

Edited by: Matteo Bonato,

University of Milan, Italy

Reviewed by:

Sandro Legey,

Universidade Veiga de Almeida, Brazil

${ }^{*}$ Correspondence:

Ambra Gentile

ambra.gentile@unipa.it

Specialty section:

This article was submitted to Movement Science and Sport

Psychology,

a section of the journal

Frontiers in Psychology

Received: 29 June 2020 Accepted: 04 September 2020 Published: 15 October 2020

Citation:

Lakicevic N, Gentile A, Mehrabi S, Cassar S, Parker K, Roklicer R, Bianco A and Drid P (2020) Make Fitness Fun: Could Novelty Be the Key

Determinant for Physical Activity

Adherence?

Front. Psychol. 11:577522.

doi: 10.3389/fpsyg.2020.577522
PA), is positively associated with numerous physical and psychological health benefits across all population subgroups (i.e., different age groups, gender, ethnicity, and socioeconomic status) (Paterson and Warburton, 2010; Warburton and Bredin, 2017). The current PA guidelines for adults, proposed by the American College for Sports Medicine and American Heart Association (ACSM/AHA), recommend the accumulation of at least $150 \mathrm{~min}$ of moderate intensity aerobic PA per week (Nelson et al., 2007). Additionally, it is recommended that adults should engage in muscle-strengthening activities at least two times per week (Garber et al., 2011). Despite this, sedentary behavior remains a major challenge, and insufficient PA rates have remained stable at the global level between 2001 and 2016 (Guthold et al., 2018). Physical inactivity is the fourth leading cause of death worldwide and its annual health-care costs have been estimated at 53.8 billion US dollars in 2012 internationally (Ding et al., 2016). However, it has recently been shown that with sufficient PA, as many as 3.9 million premature deaths could be averted annually (Strain et al., 2020), and thus more needs to be done to improve engagement and maintenance of PA throughout the lifespan.

The correlates and determinants of PA participation and maintenance are complex and diverse, and differ among various population subgroups (Thiel et al., 2018; Parker et al., 2019). This can be best described using an ecological framework which posits that there are multiple levels of influence on an individual's PA behavior including: individual (i.e., motivation, competence, preference, and self-efficacy), environmental (including the social, natural, and built environment) and policy level factors (Bauman et al., 2012). It follows that these factors are the key pillars of PA adherence, which is defined as a habitual participation in PA on a voluntary basis (Robison and Rogers, 1994).

A lack of novelty regarding an individuals' exercise routine may also be a key factor contributing to low PA participation in the general population (Dalle Grave et al., 2011). Even among active individuals, continued engagement in the same exercise over time can halt progressive overload and potentially contribute to reversibility (retraction to baseline condition) (American College of Sports et al., 2018), and can ultimately reduce motivation to participate in PA out of boredom. This seemingly vicious cycle can possibly be tackled by introducing novel exercise regimens on a regular basis. 
Generally, PA is distinguished in terms of the major metabolic pathway involved in energy contribution, predominantly aerobic or anaerobic. Aerobic and anaerobic training have shown to have positive effects on cardiovascular health (Patel et al., 2017), both separately and when combined. Indeed, the majority of PA modes include a mixture of both, thereby allowing participants to obtain benefits of both types of PA. Additionally, the introduction of new exercises in the PA routine will lead to novel skill acquisition and mastery necessary for that particular PA (Green and Bavelier, 2009). Notably, engaging in new gestures can further develop an individual's skillset, enabling an expansion of the spectrum of PA options one can participate in. Furthermore, exposing the body to a variety of novel activities leads to improvements in body composition and fitness among children (Liu et al., 2020) and adults (Wilhelm and Pinto, 2019). To this regards, youth who experience multiple sports, as a subset of PA, increase their scope for varied PA in adulthood and these experiences may foster an intrinsic motivation for lifelong participation (Mostafavifar et al., 2013). Meanwhile, as the "feel good" effect of exercise is known to differ according to intensity among individuals (Ekkekakis and Brand, 2019), varied PA participation may be an important pre-requisite for finding preferred and tolerable PA options which in turn may lead to longer term adherence. These findings underscore the importance of understanding not only the physiological effects of PA, but also the need to account for how varied PA is experienced in relation to pleasure and enjoyment. Therefore, based on the aforementioned, the aim of this work is to highlight novelty as potentially a key determinant for PA adherence.

\section{The Psychological Features of Exercise Novelty}

Few studies about the role of novelty in PA adherence exist. It is well known that intrinsic motivation predicts the PA adherence through interest (the desire to engage and expand skills), and enjoyment (the desire to have fun and pursue interest) (Richard et al., 1997; Teixeira et al., 2012; Gardner and Lally, 2013).

According to Berlyne (1970), novel stimuli may promote interest and enjoyment when they are simple, while familiar stimuli arouse interest when they contain variations that create complexity in movement variations (Sylvester et al., 2018). Therefore, performing new and challenging exercises could increase enjoyment and interest while enhancing acquisition of new skills every time a new exercise is introduced. Moreover, it has been recently hypothesized that the need for novelty, that is the need to experience something that stands out of the routine (González-Cutre et al., 2019), could be one of the Basic Psychological Needs (Bagheri and Milyavskaya, 2020; FernándezEspínola et al., 2020). In this sense, creating programs satisfying the need for novelty, and stimulating interest and enjoyment at the same time, could also promote individuals' participation over time, through the introduction of new exercises in the PA routine, or the variation of familiar exercises (Sylvester et al., 2018). For example, fitness regimes such as CrossFit, whereby participants are exposed to constantly varied functional movements, are shown to elicit higher levels of satisfaction and motivation for engagement (Claudino et al., 2018). Nevertheless, since the repeated exposure to the same stimulus could lead to a decrease in interest and enjoyment, the introduction of novel exercise should be alternated with the familiar complex exercise (Sylvester et al., 2018). Finally, enhancing intrinsic motivation through interest and enjoyment is expected to increase adherence to the PA program (Richard et al., 1997), leading to better health outcomes (Robison and Rogers, 1994).

One interesting outcome of performing new exercises, which also reinforces an individual's level of engagement, is the flow experience. Flow experience is described as a sense of concentration and absorption, with suppression of irrelevant feelings and thoughts, resulting in a deep engagement in that activity (Csikszentmihalyi and Csikszentmihalyi, 1992; Csikszentmihalyi, 2020). This state is also related to future involvement in the same situation, and can lead to increased autonomous motivation, and a reduction of boredom. In a recent study by Swann et al. (2019), the authors explored the predictors of flow state in athletes, and found that this phenomenon is more likely to occur in the context of novelty, exploration, and flexible outcomes. Therefore, flow state is induced when exercises are new, or are presented with some variations, and when low pressure or importance is placed on the outcome. In summary, the exercise features that may lead to sustained high PA engagement include novelty, challenging variation of familiar exercises, and flexible outcomes.

\section{DISCUSSION}

Engagement in long-term PA has many psychological, psychosocial and physical health benefits (Both et al., 2010; Warburton and Bredin, 2017). However, individuals' PA participation often decreases over time due to various environmental or personal factors (Calvo et al., 2010). One critical determinant ensuring long-term engagement in PA could be the reinforcement of intrinsic motivation, through interest and enjoyment. Physical activity regimens comprised of new exercises or varying familiar exercises could rise participants' interest and enjoyment and enhance their adherence to PA, ultimately leading to better health.

For example, interactive video-game systems that combine gaming and PA (also known as exergames), and exercise programs delivered via digital platforms (e.g., smartphone apps) also are plausible alternative strategies to encourage PA participation, and improve quality of life (Sween et al., 2014; Romeo et al., 2019). Exergaming through novel mediums such as virtual reality (VR), and digital behavior change apps provide a multisensory and immersive environment that is customizable to the user's functional abilities and personal preferences, and thus may increase motivation for regular PA participation or enhanced adherence (Albergoni et al., 2019; Ng et al., 2019; Stockwell et al., 2019; Bonato et al., 2020). For individuals reluctant to participate in PA, the interactive environment of exergames can create a distraction from negative thoughts about PA and encourage the individual to participate in a non-traditional environment (Molina et al., 
2014; Street et al., 2017). Further, apps that include social networking and media sites offer the additional benefits of social interaction and support shown to increase PA enjoyment and adherence (Ferrer and Ellis, 2017; Petersen et al., 2019). These platforms may be particularly useful in the current era of the COVID-19 pandemic where governments around the world have imposed quarantine measures to reduce the risk of COVID-19 infection which inevitably leads to lower PA levels in the overall population (Lakicevic et al., 2020), particularly among those who were already inactive (Hall et al., 2020). Even though the long-term of effects of COVID19 will not be fully understood for some time, this health crisis has the potential to further impact and accelerate the existing physical inactivity pandemic (Hall et al., 2020). For this reason, ACSM recently published PA guidelines emphasizing the importance of staying active while taking precautions to ensure safety in the midst of the COVID-19 pandemic (Denay et al., 2020).

Physicians represent a key figure in the dissemination of PA recommendations to a broad segment of the population, with evidence that those who are guided to perform exercise by their physician, perform more moderate-to-vigorous intensity PA than those who do not receive any exercise prescription (Taylor, 2014). This can be particularly important for older individuals who are less likely to engage in PA, compared to their younger counterparts (Gavin et al., 2014). Where an individual has previously acquired knowledge regarding safe, functional, and simple PA, medical clearance or a health appraisal prior to engaging in novel forms of PA might not be necessary. It is important to note that not all age groups will show the same level of eagerness to engage in a new form of PA (Gavin et al., 2014). Instead, varying the intensity

\section{REFERENCES}

Albergoni, A., Hettinga, F. J., La Torre, A., Bonato, M., and Sartor, F. (2019). The role of technology in adherence to physical activity programs in patients with Chronic diseases experiencing fatigue: a systematic review. Sports Med. Open 5:41. doi: 10.1186/s40798-019-0214-z

American College of Sports, M., Riebe, D., Ehrman, J. K., Liguori, G., and Magal, M. (2018). ACSM's Guidelines for Exercise Testing and Prescription. Philadelphia, PA: Wolters Kluwer.

Bagheri, L., and Milyavskaya, M. (2020). Novelty-variety as a candidate basic psychological need: new evidence across three studies. Motiv. Emot. 44, 32-53. doi: 10.1007/s11031-019-09807-4

Bauman, A. E., Reis, R. S., Sallis, J. F., Wells, J. C., Loos, R. J., Martin, B. W., et al. (2012). Correlates of physical activity: why are some people physically active and others not? Lancet 380, 258-271. doi: 10.1016/S0140-6736(12)60735-1

Berlyne, D. E. (1970). Novelty, complexity, and hedonic value. Percept. Psychophys. 8, 279-286. doi: 10.3758/BF03212593

Bonato, M., Turrini, F., Zan, VDE., Meloni, A., Plebani, M., Brambilla, E., et al. (2020). A mobile application for exercise intervention in people living with HIV. Med. Sci. Sports Exerc. 52, 425-433. doi: 10.1249/MSS.0000000000002125

Both, F., Hoogendoorn, M., Klein, M. C., and Treur, J. (2010). "Computational modeling and analysis of the role of physical activity in mood regulation and depression," in: International Conference on Neural Information Processing (Springer), 270-281.

Calvo, T. G., Cervelló, E., Jiménez, R., Iglesias, D., and Murcia, J. A. M. (2010). Using self-determination theory to explain sport persistence and dropout in adolescent athletes. Span. J. Psychol. 13, 677-684. doi: $10.1017 /$ S1138741600002341 may provide the stimulus and novelty required to increase PA adherence and elicit significant health benefits. One plausible approach might be interval training, whereby the intensity of movement is intermittently varied. Studies have shown that interval training can improve enjoyment (Stork et al., 2017), affective response (Niven et al., in press), and mental and physiological adaptations (Martland et al., 2020) in comparison to continuous moderate intensity exercise. Finally, enjoyment is an important factor mediating the level of PA adherence (Wankel, 1993; Jekauc, 2015).

Knowing that non-communicable diseases are the leading threat to public health on a global scale (Thornton et al., 2016), the importance of regular PA, as a therapeutic agent tackling non-communicable diseases, cannot be overestimated. To increase the overall population rate of adherence to ACSM/AHA guidelines, we believe that novelty can play a key part in helping individuals reach these recommendations. Accordingly, physicians, researchers, and practitioners should place a special emphasis on novelty, as, potentially, one of the key determinants contributing to PA adherence. Ultimately, engaging in PA that is enjoyable, improves health and wellbeing, and provides continual novel stimulus, will lead to improved engagement and adherence over time.

\section{AUTHOR CONTRIBUTIONS}

NL, AG, AB, and PD contributed to conception and design of the study and wrote the first draft of the manuscript. SM, SC, KP, and RR wrote sections of the manuscript. All authors contributed to manuscript revision, read, and approved the submitted version.
Claudino, J. G., Gabbett, T. J., Bourgeois, F., Souza, H. S., Miranda, R. C., Mezencio, B., et al. (2018). CrossFit overview: systematic review and meta-analysis. Sports Med. Open 4:11. doi: 10.1186/s40798-018-0124-5

Csikszentmihalyi, M. (2020). Finding flow: The psychology of engagement with everyday life. London, UK: Hachette UK.

Csikszentmihalyi, M., and Csikszentmihalyi, I. S. (1992). Optimal Experience: Psychological Studies of Flow in Consciousness. Cambridge: Cambridge University Press.

Dalle Grave, R., Calugi, S., Centis, E., El Ghoch, M., and Marchesini, G. (2011). Cognitive-behavioral strategies to increase the adherence to exercise in the management of obesity. J. Obes. 2011:348293. doi: 10.1155/2011/ 348293

Denay, K. L., Breslow, R. G., Turner, M. N., Nieman, D. C., Roberts, W. O., and Best, T. M. (2020). ACSM call to action statement: COVID-19 considerations for sports and physical activity. Curr. Sports Med. Rep. 19, 326-328. doi: 10.1249/JSR.0000000000000739

Ding, D., Lawson, K. D., Kolbe-Alexander, T. L., Finkelstein, E. A., Katzmarzyk, P. T., van Mechelen, W., et al. (2016). The economic burden of physical inactivity: a global analysis of major non-communicable diseases. Lancet 388, 1311-1324. doi: 10.1016/S0140-6736(16)30383-X

Ekkekakis, P., and Brand, R. (2019). Affective responses to and automatic affective valuations of physical activity: fifty years of progress on the seminal question in exercise psychology. Psychol. Sport Exerc. 42, 130-137. doi: 10.1016/j.psychsport.2018.12.018

Fernández-Espínola, C., Almagro, B. J., Tamayo-Fajardo, J. A., and Sáenz-López, P. (2020). Complementing the self-determination theory with the need for novelty: motivation and intention to be physically active in physical education students. Front. Psychol. 11:1535. doi: 10.3389/fpsyg.2020.01535 
Ferrer, D. A., and Ellis, R. (2017). A review of physical activity interventions delivered via facebook. J. Phys. Act. Health 14, 823-833. doi: 10.1123/jpah.2016-0534

Garber, C. E., Blissmer, B., Deschenes, M. R., Franklin, B. A., Lamonte, M. J., Lee, I. M., et al. (2011). American college of sports medicine position stand. Quantity and quality of exercise for developing and maintaining cardiorespiratory, musculoskeletal, and neuromotor fitness in apparently healthy adults: guidance for prescribing exercise. Med. Sci. Sports Exerc. 43, 1334-1359. doi: 10.1249/MSS.0b013e318213fefb

Gardner, B., and Lally, P. (2013). Does intrinsic motivation strengthen physical activity habit? Modeling relationships between self-determination, past behaviour, and habit strength. J. Behav. Med. 36, 488-497. doi: 10.1007/s10865-012-9442-0

Gavin, J., Keough, M., Abravanel, M., Moudrakovski, T., and McBrearty, M. (2014). Motivations for participation in physical activity across the lifespan. Int. J. Wellbeing 4, 46-61. doi: 10.5502/ijw.v4i1.3

González-Cutre, D., Romero-Elías, M., Jiménez-Loaisa, A., Beltrán-Carrillo, V. J., and Hagger, M. S. (2019). Testing the need for novelty as a candidate need in basic psychological needs theory. Motiv. Emot. 44, 295-314. doi: 10.1007/s11031-019-09812-7

Green, C., and Bavelier, D. (2009). Exercising your brain: a review of human brain plasticity and training-induced learning. Psychol. Aging 23, 692-701. doi: $10.1037 / \mathrm{a} 0014345$

Guthold, R., Stevens, G. A., Riley, L. M., and Bull, F. C. (2018). Worldwide trends in insufficient physical activity from 2001 to 2016: a pooled analysis of 358 population-based surveys with 19 million participants. Lancet Global Health 6, e1077-e1086. doi: 10.1016/S2214-109X(18) 30357-7

Hall, G., Laddu, D. R., Phillips, S. A., Lavie, C. J., and Arena, R. (2020). A tale of two pandemics: how will COVID-19 and global trends in physical inactivity and sedentary behavior affect one another? Prog. Cardiovasc. Dis. doi: 10.1016/j.pcad.2020.04.005. [Epub ahead of print].

Jekauc, D. (2015). Enjoyment during exercise mediates the effects of an intervention on exercise adherence. Psychology 6, 48-53. doi: 10.4236/psych.2015.61005

Lakicevic, N., Moro, T., Paoli, A., Roklicer, R., Trivic, T., Cassar, S., et al. (2020). Stay fit, don't quit: geriatric exercise prescription in COVID-19 pandemic. Aging Clin. Exp. Res. 32, 1209-1210. doi: 10.1007/s40520-02001588-y

Liu, J., Zhu, L., and Su, Y. (2020). Comparative effectiveness of high-intensity interval training and moderate-intensity continuous training for cardiometabolic risk factors and cardiorespiratory fitness in childhood obesity: a meta-analysis of randomized controlled trials. Front. Physiol. 11, 214-214. doi: 10.3389/fphys.2020. 00214

Martland, R., Mondelli, V., Gaughran, F., and Stubbs, B. (2020). Can high-intensity interval training improve physical and mental health outcomes? A meta-review of 33 systematic reviews across the lifespan. J. Sports Sci. 38, 430-469. doi: 10.1080/02640414.2019.17 06829

Molina, K. I., Ricci, N. A., de Moraes, S. A., and Perracini, M. R. (2014). Virtual reality using games for improving physical functioning in older adults: a systematic review. J. Neuroeng. Rehabil. 11:156. doi: 10.1186/1743-0003$11-156$

Mostafavifar, A. M., Best, T. M., and Myer, G. D. (2013). Early sport specialisation, does it lead to long-term problems? Br. J. Sports Med. 47, 1060-1061. doi: 10.1136/bjsports-2012-092005

Nelson, M. E., Rejeski, W. J., Blair, S. N., Duncan, P. W., Judge, J. O., King, A. C., et al. (2007). Physical activity and public health in older adults: recommendation from the American college of sports medicine and the American heart association. Med. Sci. Sports Exerc. 39, 1435-1445. doi: 10.1249/mss.0b013e3180616aa2

Ng, Y.-L., Ma, F., Ho, F. K., Ip, P., and Fu, K.-,w. (2019). Effectiveness of virtual and augmented reality-enhanced exercise on physical activity, psychological outcomes, and physical performance: a systematic review and meta-analysis of randomized controlled trials. Comput. Human Behav. 99, 278-291. doi: 10.1016/j.chb.2019.05.026
Niven, A., Laird, Y., Saunders, D. H., and Phillips, S. M. (in press). A systematic review and meta-analysis of affective responses to acute high intensity interval exercise compared with continuous moderate-and highIntensity exercise. Health Psychol. Rev. 1-34. doi: 10.1080/17437199.2020.17 28564

Parker, K. E., Salmon, J., Villanueva, K., Mavoa, S., Veitch, J., Brown, H. L., et al. (2019). Ecological correlates of activity-related behavior typologies among adolescents. BMC Public Health 19:1041. doi: 10.1186/s12889-0197386-9

Patel, H., Alkhawam, H., Madanieh, R., Shah, N., Kosmas, C. E., and Vittorio, T. J. (2017). Aerobic vs anaerobic exercise training effects on the cardiovascular system. World J. Cardiol. 9, 134-138. doi: 10.4330/wjc.v9.i2.134

Paterson, D. H., and Warburton, D. E. (2010). Physical activity and functional limitations in older adults: a systematic review related to Canada's physical activity guidelines. Int. J. Behav. Nutr. Phys. Act. 7:38. doi: 10.1186/14795868-7-38

Petersen, J. M., Prichard, I., and Kemps, E. (2019). A comparison of physical activity mobile apps with and without existing web-based social networking platforms: systematic review. J. Med. Internet Res. 21:e12687. doi: 10.2196/ 12687

Richard, M., Christina, M. F., Deborah, L. S., Rubio, N., and Kennon, M. S. (1997). Intrinsic motivation and exercise adherence. Int. J. Sport Psychol. 28, 335-354.

Robison, J. I., and Rogers, M. A. (1994). Adherence to exercise programmes. Recommendations. Sports Med. 17, 39-52. doi: 10.2165/00007256-19941701000004

Romeo, A., Edney, S., Plotnikoff, R., Curtis, R., Ryan, J., Sanders, I., et al. (2019). Can smartphone apps increase physical activity? Systematic review and metaanalysis. J. Med. Inter. Res. 21:e12053. doi: 10.2196/12053

Stockwell, S., Schofield, P., Fisher, A., Firth, J., Jackson, S. E., Stubbs, B., et al. (2019). Digital behavior change interventions to promote physical activity and/or reduce sedentary behavior in older adults: a systematic review and meta-analysis. Exp. Gerontol. 120, 68-87. doi: 10.1016/j.exger.2019. 02.020

Stork, M. J., Banfield, L. E., Gibala, M. J., and Martin Ginis, K. A. (2017). A scoping review of the psychological responses to interval exercise: is interval exercise a viable alternative to traditional exercise? Health Psychol. Rev. 11, 324-344. doi: $10.1080 / 17437199.2017 .1326011$

Strain, T., Brage, S., Sharp, S. J., Richards, J., Tainio, M., Ding, D., et al. (2020). Use of the prevented fraction for the population to determine deaths averted by existing prevalence of physical activity: a descriptive study. Lancet Global Health 8, e920-e930. doi: 10.1016/S2214-109X(20) 30211-4

Street, T. D., Lacey, S. J., and Langdon, R. R. (2017). Gaming your way to health: a systematic review of exergaming programs to increase health and exercise behaviors in adults. Games Health J. 6, 136-146. doi: 10.1089/g4h.2016. 0102

Swann, C., Jackman, P. C., Schweickle, M. J., and Vella, S. A. (2019). Optimal experiences in exercise: a qualitative investigation of flow and clutch states. Psychol. Sport Exerc. 40, 87-98. doi: 10.1016/j.psychsport.2018. 09.007

Sween, J., Wallington, S. F., Sheppard, V., Taylor, T., Llanos, A. A., and AdamsCampbell, L. L. (2014). The role of exergaming in improving physical activity: a review. J. Phys. Act. Health 11, 864-870. doi: 10.1123/jpah.2011-0425

Sylvester, B. D., Jackson, B., and Beauchamp, M. R. (2018). The effects of variety and novelty on physical activity and healthy nutritional behaviors. $A d v$. Motivat. Sci. 5, 169-202. doi: 10.1016/bs.adms.2017.11.001

Taylor, D. (2014). Physical activity is medicine for older adults. Postgrad. Med. J. 90, 26-32. doi: 10.1136/postgradmedj-2012-131366

Teixeira, P. J., Carraça, E. V., Markland, D., Silva, M. N., and Ryan, R. M. (2012). Exercise, physical activity, and self-determination theory: a systematic review. Int. J. Behav. Nutr. Phys. Act. 9:78. doi: 10.1186/1479-5868-9-78

Thiel, A., Thedinga, H. K., Barkhoff, H., Giel, K., Schweizer, O., Thiel, S., et al. (2018). Why are some groups physically active and others not? A contrast group analysis in leisure settings. BMC Public Health 18:377. doi: 10.1186/s12889-018-5283-2

Thornton, J. S., Frémont, P., Khan, K., Poirier, P., Fowles, J., Wells, G. D., et al. (2016). Physical activity prescription: a critical opportunity to address a 
modifiable risk factor for the prevention and management of chronic disease: a position statement by the Canadian academy of sport and exercise medicine. Br. J. Sports Med. 50, 1109-1114. doi: 10.1136/bjsports-2016-096291

Wankel, L. M. (1993). The importance of enjoyment to adherence and psychological benefits from physical activity. Int. J. Sport Psychol. 24, 151-169.

Warburton, D. E. R., and Bredin, S. S. D. (2017). Health benefits of physical activity: a systematic review of current systematic reviews. Curr. Opin. Cardiol. 32, 541-556. doi: 10.1097/HCO.0000000000000437

Wilhelm, E. N., and Pinto, R. S. (2019). "Concurrent aerobic and strength training for body composition and health," in Concurrent Aerobic and Strength Training (Springer), 293-307. doi: 10.1007/978-3-319-75547-2_19
Conflict of Interest: The authors declare that the research was conducted in the absence of any commercial or financial relationships that could be construed as a potential conflict of interest.

Copyright (๑) 2020 Lakicevic, Gentile, Mehrabi, Cassar, Parker, Roklicer, Bianco and Drid. This is an open-access article distributed under the terms of the Creative Commons Attribution License (CC BY). The use, distribution or reproduction in other forums is permitted, provided the original author(s) and the copyright owner(s) are credited and that the original publication in this journal is cited, in accordance with accepted academic practice. No use, distribution or reproduction is permitted which does not comply with these terms. 